\title{
VENTAJAS ADICIONALES DE UN PROGRAMA DE NECESIDADES
}

\author{
(ADDITIONAL BENEFITS FROM A PROGRAMME OF NECESSITIES)
}

\author{
Alberto Oroviogoicoechea, Dr. Ing. Industrial \\ Marcos Cortada, Dr. Arquitecto \\ Ingenieria IDOM
}

$107-1$

\begin{abstract}
RESUMEN
Además de la importancia que tiene para el Proyectista de un edificio disponer de un Programa de Necesidades detallado del mismo, se describen en el presente articulo las ventajas que aportan al futuro usuario las reflexiones que ha de hacer durante la elaboración de dicho Programa.
\end{abstract}

Pasando revista a diversos capitulos de un Programa de Necesidades, se comentan las aportaciones que puede conseguir una buena dirección en la elaboración del mismo, y que no sólo lo enriquecen, sino que consiguen efectos internos beneficiosos para el propio usuario, en temas tales como organización, programación, integración de personal, conocimiento propio, etc.

\author{
SUMMARY \\ This work comments the importance that can have, for a building \\ Planer, to have at his disposal a Programme of Necessities. \\ It also comments the advantages the user could obtain in the \\ future by his own contribution in the elaboration of this \\ Programme. \\ The work reviews the chapters of a Programme of Necessities and \\ describes the contribution that can be obtained by means of a good \\ management in its elaboration. Those contributions not only make \\ it richer, but get profitable inner effects for the user himself, \\ in such themes as organization, programming, personal integration, \\ own knowledgement, etc.
}

\section{Introducción}

Aunque nos referimos en este artículo a los casos de edificios de tipo técnico-administrativo, la mayor parte de las conclusiones, y sobre todo las de tipo general, pueden aplicarse a cualquier proyecto con su Programa de Necesidades (PN) previo.

Creemos que el PN debe, por un lado, llevar al usuario a pensar a fondo en todos los aspectos del futuro proyecto; por otro, debe plasmar en forma concreta todos los datos pero sin coartar la iniciativa del Proyectista.

Nunca se debe redactar un PN al margen del futuro usuario o sólo en contacto con su alta dirección, sino que debe conseguir la integración de los distintos niveles de la empresa, mediante:

\section{- Encuestas generales a todo el personal.}

- Elaboración de las primeras propuestas en un Grupo de Trabajo, en el que se integren algunas personas significativas de la empresa.

- Formación de un Comité de altos responsables que tome las decisiones de qué se pide al proyecto.
- Aprobación de las decisiones al máximo nivel de la empresa.

Hay que lograr la debida justificación de peticiones de necesidades para la nueva sede y para ello hacer profundizar, razonar, concretar y defender esas peticiones.

Por supuesto, quienes redactan el PN deben, además de dominar los aspectos tecnológicos de la edificación, reunir grandes dotes de paciencia y sentido común: el usuario tiene muchas ideas y hay que saber ayudar a sacarlas, pulirlas y plasmarlas. No olvidemos que tiene siempre poco tiempo para el PN y, sin embargo, es fundamental que piense en ese futuro que está encargando.

Finalmente, para que el futuro autor del Proyecto saque la máxima utilidad del PN, si está designado desde el principio por el Cliente, debe participar con cierta frecuencia en las reuniones del Grupo de Trabajo que elabora el PN. Si no está designado - cuando el PN forma parte de la documentación de un concurso de Proyectistas - será conveniente prever una etapa de coordinación, con intervención de los autores del PN en la fase inicial del anteproyecto. 


\section{Estudio previo de solares}

Sin duda, es quizá uno de los primeros en los que el redactor del PN puede aportar condicionantes que, aunque lógicos, pueden no haber sido tenidos en cuenta por el usuario al pensar en «aquel» terreno para la Nueva Sede y que, por otro lado, son básicos para las fases de anteproyecto y proyecto.

Y así, se da cuenta de que la geotecnia, urbanismo, transportes públicos y equipamiento, por citar algunos de los más importantes, llevan a la eliminación de muchas previsiones, muy acertadas por cierto si sólo se valoran otros aspectos.

\section{Tipologías}

El PN debe reunir las impresiones subjetivas de los usuarios para definir en forma resumida, pero clara, las características tipológicas tanto exteriores como interiores de los futuros edificios (imagen, estilo, volumetría, confort, etc.), y aquí se verá que no es tan sencillo concretar a pesar de que se trata de rasgos generales.

Surgirán aparentes discrepancias donde parecía que "ya» se sabía perfectamente lo que se quería; no obstante no son tales discrepancias, sino enriquecimiento de ideas que el redactor del PN debe saber resumir y concretar.

El resultado será que, desde las primeras concepciones del Proyectista, el Cliente no se encuentre con un producto extraño y ajeno a sus preferencias estéticas.

\section{Situación actual}

Para proyectarse hacia la situación futura, un buen PN debe plasmar la situación actual como base de aquélla.

$\mathrm{Al}$ recoger los datos se ven realmente los problemas que existen, conocidos sólo por informes, reclamaciones, etc., dispersos en el lugar y en el tiempo.

Es donde comienzan a apuntarse las necesidades reales del futuro (también las supérfluas). Se ve lo que sobra (fuera de uso) y lo verdaderamente necesario.

Quedan justificadas algunas malas impresiones y, en cambio, se descubre la falsedad de otras apreciaciones organizativas, de funcionamiento, etc.

Sin duda, los datos que aporta esta fase del PN constituyen una guía muy importante para que la Alta Dirección pueda ordenar ideas cara al futuro.

El PN debe conseguir que el Cliente se enfrente con sus propias debilidades y fortalezas y pueda plantearse la situación de futuro más acorde con sus necesidades.

\section{Encuestas}

Para "sacar» los datos para el PN, tanto actuales como de futuro, es normal recurrir al sistema de encuestas. ¿Qué se logra con ellas?

Creemos que lo primero que logramos es la integración de las personas en el nuevo proyecto; la desmitificación del fantasma y el apoyo al traslado de sede ante el cual siempre existe un recelo. El diálogo generalizado aporta claridad y comprensión, y puede matizar allí donde no llega una comunicación por muy amplia que sea.

Los propios Jefes de Departamento descubren a veces matices del funcionamiento real de los mismos. Al estudiar las interrelaciones se ve que sobran a veces copias, papeles de comunicación, controles, etc., así como de los usos reales de teléfonos, telex, cable, radio, etc., lográndose apuntar ya por los propios usuarios a soluciones de futuro más simplificadas y centralizadas.

Lo mismo ocurre en el tema de reuniones y visitas, ¿por qué y para qué tantas o tan pocas? Son reflexiones que surgen de datos objetivos sacados del mismo personal, que hacen decantar ideas que, sin el PN, serían «imposiciones de la Dirección».

Las encuestas de inventario dan también una idea clara de las disponibilidades de mobiliario y equipamiento actuales y su aprovechamiento para el futuro. Además se ponen de manifiesto las insuficiencias en unos departamentos y los excesos en otros, lo que permitirá una mejor redistribución de medios en el Proyecto.

Creemos que con estas encuestas se configura el tipo de empresa desde el punto de vista social, se centra no sólo lo que se quiere, sino lo que no se quiere, se define mucho más de lo que se pensaba en un principio y sirve de gran ayuda para la Dirección de Organización de la Empresa.

\section{Organigramas}

Junto con las previsiones de futuro se suele pensar también en retoques de los organigramas existentes.

Pero es al hacer las encuestas y resumirlas cuando surge el verdadero funcionamiento, que no siempre coincide con el organigrama oficial, y así, para una nueva sede, se pueden disponer las personas de forma que realmente funcione el Organigrama Oficial que establezca, normalmente enriquecido con los datos aportados por las encuestas sobre el verdadero funcionamiento. Suele ser el momento en que se ven claros ciertos retoques a la vista de la realidad.

\section{Políticas de crecimiento}

El concepto es sencillo: ¿a dónde queremos ir en el futuro? 
Para llegar a él surgen las discusiones y forcejeos a todos los niveles; primero se fija un crecmiento de arriba hacia abajo y luego llegan los datos y peticiones de abajo hacia arriba; flujo y reflujo de opiniones, deseos o razones.

Es quizá la fase más importante y más difícil de centrar, ya que las ideas claras que se tenían se demuestra que aún no lo estaban. Se da vueltas al tema y con la colaboración de todos, sale al final una solución centrada y sobre todo participada.

Se ha logrado un proyecto de futuro coordinado y comprometido por parte de todos.

\section{Asignación de espacios}

No cabe duda que un buen PN debe llegar a determinar, con la mayor precisión posible, las necesidades espaciales.

Por otro lado, es siempre un problema de las personas establecer comparaciones con otras de la organización, con la creación de las consiguientes tensiones.

Se evitan los problemas, salvando los resultados, mediante la asignación de prototipos de áreas de trabajo por niveles amplios de funciones a desarrollar, prototipos que no son equipamientos concretos de puestos de trabajo, sino conjuntos que dan lugar a un área total con la que se trabaja en el PN.

\section{Instalaciones}

Con la aportación de unos criterios básicos del redactor del PN, y como consecuencia de las encuestas sobre este tema, hay que lograr, y se logra, dar funcionalidad y flexibilidad a los servicios, al mismo tiempo que el personal de mantenimiento queda satisfecho y comprometido para el futuro.

También queda clara la no necesidad de ciertos "caprichos» que costarían muy caros y que «nadie los va a tener».

En una palabra, mediante el diálogo se llega finalmente a convencer, y no vencer, planteando unas instalaciones realmente suficientes, flexibles y razonables en costo.

\section{Informática}

Con los avances de este medio en todos los campos de la empresa, suele ser difícil establecer el equilibrio serviciocosto para que el PN lleve a un proyecto encajado en el tiempo.

Sin embargo, es preciso un trabajo a conciencia para conjugar el costo elevado de áreas especiales en equipamiento y seguridad con la flexibilidad, cara al futuro, entre la Dirección de Informática que pide y la Dirección General que mide el precio.
Generalmente, hablando del centro de cálculo, cuando se está pensando en el traslado a una nueva sede, suele dar lugar a un crecimiento enorme, que es preciso meditar para llegar a mínimos razonables, dando gran disponibilidad de terminales de pantallas administrativas o informativas de salida y siendo más estrictos en áreas de entrada de datos que son las caras.

\section{Seguridad}

Tema importante en cierto tipo de edificios; más reciente que la informática, pero que también exige previsiones de futuro y condiciona muchos elementos de los edificios.

La zonificación por niveles de seguridad es una de las variables más importantes, por la repercusión que tiene en el edificio al tener que conjugarla con las exigencias de la organización del trabajo.

Hay que hacer reflexionar al usuario para no llegar a grados de sofisticación que pueden perjudicar gravemente el funcionamiento.

Por el lado contrario, habrá que llevarle a no despreciar la seguridad, al menos en planteamiento de previsión de futuro (en lo que afecta a la obra gruesa o fija), ya que el no hacerlo puede obligar en el futuro a obras muy costosas o incluso a tener que reducir niveles de seguridad.

\section{Servicios especiales}

Nos referimos a comedores, cafetería, aparcamientos, zonas de descanso, etc.

Es preciso también pensar no sólo cómo y dónde se prevén, sino incluso si son necesarios o no, ya que ello puede configurar realmente un ambiente distinto de la empresa, una jornada laboral determinada, un medio de transporte condicionado.

No se puede olvidar que son metros cuadrados a construir que inciden fuertemente en el presupuesto.

\section{Planificación}

Aunque es normal que sea un punto importante de un proyecto, estimamos que lo es más aún de un $\mathrm{PN}$, juzgando con realismo las fechas para los futuros nuevos edificios.

Debe incluir, por supuesto, el tiempo y planificación del propio PN, fijando los de las tomas de decisiones del Cliente; se completará con todo lo relativo a las fases de anteproyecto, proyecto y construcción.

Una visión realista de esta planificación al avanzar el $\mathrm{PN}$, puede llevar al Cliente a tomar decisiones que no había previsto realizar en esos momentos, en todos los 
órdenes, tales como organización, planificación financiera, selección de terrenos, etc.

\section{Conclusión}

Queda de manifiesto cómo la redacción de un Programa de Necesidades, además de las ventajas directas cara a las fases de anteproyecto y proyecto, aporta otras marginales pero muy importantes, a veces intangibles, derivadas de la reflexión e integración del usuario a las que, por tanto, debe llevarle el redactor del Programa.

$$
\text { is is is }
$$

\section{publicaciones del I.E.T.c.c.}

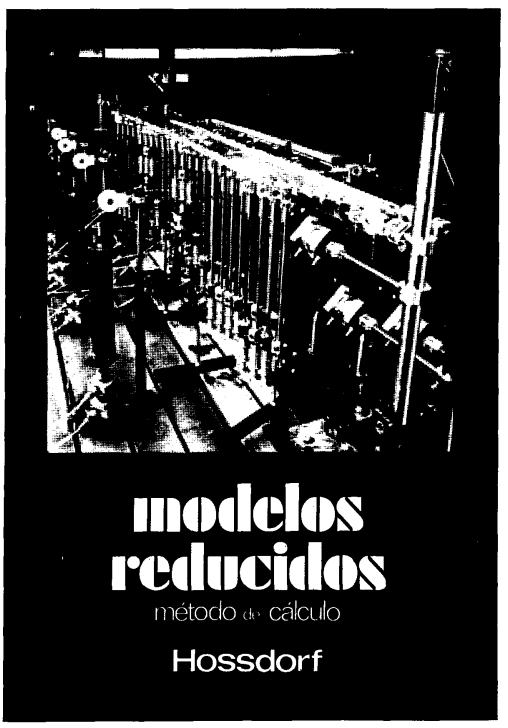

Modelos reducidos. Método de cálculo

H. Hossdorf, Ingeniero Civil

La técnica de los ensayos en modelos reducidos de estructuras sufre hoy dia una decisiva metamorfosis. Hasta hace poco era un medio más bien de artesania, que no siempre era tomado en serio por los académicos teorizantes para comprender el comportamiento resistente de las estructuras complejas $\mathrm{y}$ al que se acudió las más de las veces, como a un último remedio debido a sus indiscutibles insuficiencias. Sin embargo, en poco tiempo y gracias a su conexión con los ordenadores digitales, se ha transformado en un instrumento cientificamente valioso que no puede quedar a un lado en la práctica diaria del Ingeniero Proyectista.

Un volumen encuadernado en cartoné plastificado con lomo de tela, de $17 \times 24 \mathrm{~cm}$, compuesto de 250 páginas, 158 figuras y fotografias.

Precios: 1.800 ptas.; \$ USA 26.00

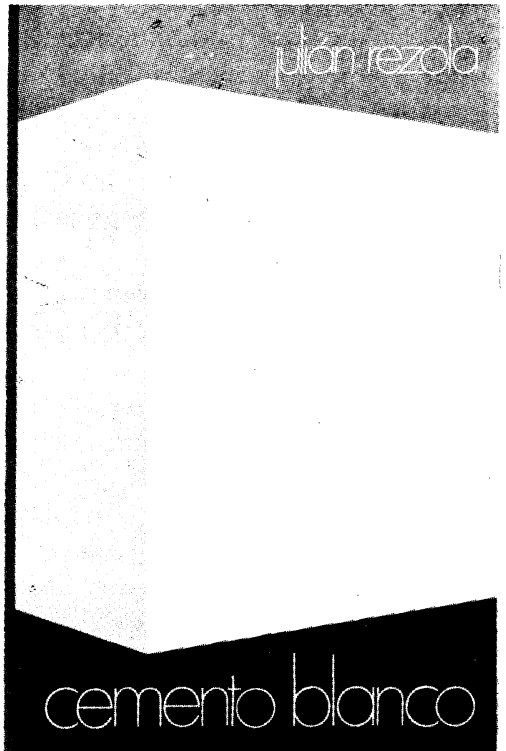

Cemento blanco

Julián Rezola

Ingeniero Químico Dipl. I. Q. S.

Sabido es que existe una extensa y documentada bibliografía sobre el cemento gris: en cambio, no puede decirse to mismo acerca del cemento portland blanco, ya que los escritos existentes se refieren ta sólo a algunas peculiaridades que le distinguen de aquél.

El autor nos ofrece sus profundos conocimientos y su larga experiencia tanto en laboratorio como y su larga expricación.

La parte descriptiva del libro se complementa con gráficos, diagramas y fotografias de gran utilidad, destinados a conseguir la aplicación apropiada de este aglomerante.

Un volumen encuadernado en cartoné policerado, de $17,4 \times 24,3 \mathrm{~cm}$, compuesto de 395 páginas, numerosas figuras, tablas $y$ ábacos.

Precios: España, 1.700 ptas.; extranjero, $\$ 34$.

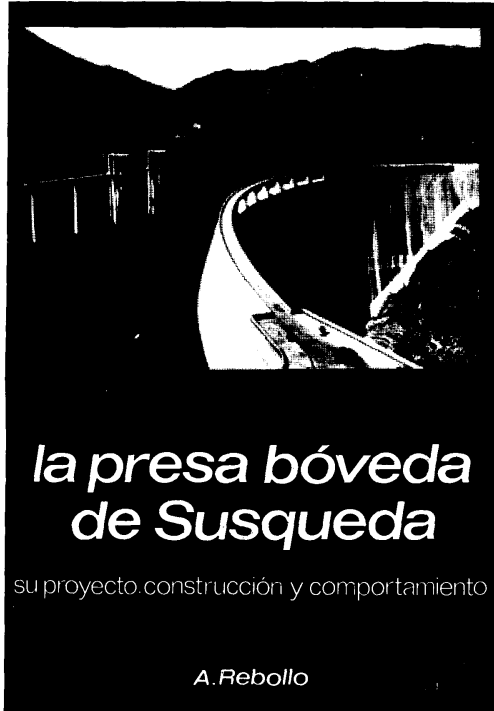

La presa bóveda de Susqueda

A. Rebollo,

Dr. Ingeniero de Caminos

El esfuerzo del constructor de presas se sitúa por su pretensión de perennidad, a contracorrient rizada por lo fungible. Pueden evocarse las 10.000 grandes presas en funcionamiento 0 en construcción que están envejeciendo y reclaman los cuidados gerontológicos para mantener y perfeccionar su servicio y garantizar su inalienable pretensión su perennidad. En la medida en que todas nuevas obras, grandes o pequeñas, son portadoras de riesgos ecológicos $y$, a veces, catastróficos, que aumentan con el envejecimiento, la gerontologia de las presas es todo un emplazo. La acción adelantada de Arturo Rebollo en este terreno marca un camino a seguir para todos los que aman su propia obra con la devoción paternal que él ha puesto en Susqueda.

Un volumen encuadernado en cartoné plastificado con lomo de tela, de $18 \times 24,5 \mathrm{~cm}$, compuesto de 408 páginas, 330 figuras $y$ fotografias y 39 tablas. Precios: 1.700 ptas.; extranjero, \$ USA 24.00 . 